\title{
Relationships between Russian mothers and their children with, and without, cancer: A controlled study
}

\author{
Aralova $\mathrm{M}^{1}$, Robertson $\mathrm{EG}^{* 2,3}$, Putrya $\mathrm{A}^{1}$, Goncharova $\mathrm{L}^{4}$, Wakefield $\mathrm{CE}^{2,3}$, Aslanyan $\mathrm{K}^{4}$ \\ ${ }^{1}$ Psychophysiology and Clinical Psychology Department, Southern Federal University, Rostov-on-Don, Russia \\ ${ }^{2}$ Behavioural Sciences Unit proudly supported by the Kids With Cancer Foundation, Kids Cancer Centre, Sydney Children's \\ Hospital, NSW, Australia \\ ${ }^{3}$ Discipline of Paediatrics, School of Women's and Children's Health, UNSW Medicine, The University of New South Wales, \\ Randwick, NSW, Australia \\ ${ }^{4}$ Center for Pediatric Oncology and Hematology, Regional Children's Hospital, Rostov-on-Don, Russia
}

Received: April 1, 2016

DOI: $10.5430 /$ ijh.v2n2p73
Accepted: June 7, 2016

URL: http://dx.doi.org/10.5430/ijh.v2n2p73
Online Published: July 13, 2016

Online $2 \mathrm{p} 73$

\begin{abstract}
Using a traditional Russian framework to understand parent-child relationships, we investigated the development of the motherchild relationship in consideration of mothers' distress and their children with cancer. Mothers of children with $(n=26)$ and without cancer $(\mathrm{n}=26)$ completed the "Family Relationship Analysis" (FRA) and "Distress Thermometer" questionnaires. Children of participating parents (ages 6-12) (26 with cancer, 26 without cancer) completed the graphic discussion "My Social Circle" to determine the child's close relationships. All mothers and children participated in the "The Cooperation Test (CT)" to assess parent-child interactions.

Distress was higher in mothers of children with cancer, with groups of mothers differing in methods for reducing distress. High distress was associated with ignoring their child's needs and excessiveness of demands/duties. Mothers of children with cancer indulged their children's demands and were more overprotective than mothers of healthy children. Children with cancer also placed their mothers further away in their social circle than children without. Overall, a clear interconnection between mother's distress and the characteristics of the mother-child relationship were found. These findings will contribute to interventions aimed at decreasing maternal distress and improving mother-child relationships in pediatric oncology.
\end{abstract}

Key Words: Cancer, Child, Mother, Distress, Interaction, Coping

\section{INTRODUCTION}

The relationship between a mother and child is particularly important for children with cancer. ${ }^{[1]}$ Increased stressors that accompany a child's diagnosis may negatively impact the nature of this relationship. ${ }^{[2-4]}$ In Russian psychology, a mother's attitude towards their child is viewed as a multidimensional entity. ${ }^{[5]}$ These dimensions can be empirically examined by investigating the mother-child connection, with particular emphasis on the mother's attitude towards her child. ${ }^{[6]}$ Russian literature identifies three inherent components of a mother's attitude that are related to the child's developmental outcomes. These include: (1) the acceptance or rejection of the child, (2) interpersonal distance between mother and child, and (3) the nature of control of the mother

\footnotetext{
*Correspondence: Robertson EG; Email: eden.robertson@unsw.edu.au; Address: Kids Cancer Centre, Sydney Children’s Hospital, Randwick 2301, NSW, Australia.
}

Published by Sciedu Press 
over the child's behaviour. ${ }^{[7]}$ These echo those considered as significant in Western literature, for example warmth and acceptance, coldness and rejection, and restrictiveness or permissiveness. ${ }^{[8]}$

Parental attitude towards their child can influence the specific type of parenting style, ultimately predicting parental behaviour and a child's development. ${ }^{[9]}$ Russian literature categorizes these parenting styles as strict, explicative, autonomous, compromising, facilitatory, sympathetic, indulgent, situational, and dependency. ${ }^{[10]}$ These are comparable to the American work of Baumrind's, ${ }^{[11]}$ which was later adapted by Maccoby and Martin, ${ }^{[12]}$ who outlined four parenting styles: authoritarian, authoritative, permissive or rejecting-neglecting. Poor parenting behaviors significantly contribute to childhood behavioral disorders and the formation of conduct problems. ${ }^{[13]}$ According to the Russian literature, established combinations of poor parenting creates six distinctive disharmonic upbringing styles: indulgent hyper-protection, dominance of hyper-protection, hypoprotection, emotional rejection, excessive moral responsibility, and abuse. ${ }^{[14]}$

The mother-child relationship becomes may be even more pertinent for ill-children. ${ }^{[15]}$ Childhood illness can intensify a child's dependency and feelings of vulnerability, and an increased mutual dependency in the mother-child relationship can develop. ${ }^{[16]}$ This mutual state of reliance has been termed as "engulfment"- an inability of the carer to separate themselves from the suffering of the cared-for person. ${ }^{[17]}$ Similarly, Young and colleagues ${ }^{[18]}$ coined the term "obligation of proximity", which refers to mothers' needs to be physically close to the sick child, and to reorganize their everyday life around them.

Russian literature has frequently published descriptions of ill children's mothers and their intra-family relationships. ${ }^{[19-21]}$ Previous Russian research assessed characteristics of the relationship between mothers and their child with cancer using a Russian sample. ${ }^{[22]}$ They identified several parenting practices such as hyper-protection, lack of punishment and limited expectations on the child. Hyper-protection and limited expectations of the child can be the prevailing features of the parenting style of mothers' of ill children, ${ }^{[20]}$ with mothers of ill children also less likely to punish or scold their children, with children being held less responsible for misbehaviour. ${ }^{[23,24]}$ Communication patterns between children and their parents may also be affected by childhood illness. Parents' communication with their ill child have been described in Russian literature as being emotionally restrictive (rare moments of tenderness, avoiding eye contact, bodily rigidity); inadequate response to the actions of the child; and more formal contact, and less non-verbal forms of communication than parents of well children. ${ }^{25]}$

Current literature contains little information regarding the nature of the interaction between mothers and their children with a cancer diagnosis. There is limited data detailing the prevalence and subsequent implications of maternal distress in children with cancer, and there is currently no data available on the attitudes these children hold towards their mothers. Moreover, the psychological characteristics of the interaction between mothers and their children with cancer have not yet been studied using a Russian framework. This study aimed to:

1) explore the relationship between Russian mothers and their children with cancer in comparison to mothers of healthy children, and

2) assess ways in which mothers of children with cancer cope with stress, in comparison to mothers of healthy children.

\section{METHOD}

\subsection{Participants}

The study consisted of 26 mother-child pairs with children who are either currently in remission or undergoing treatment from the Onco-hematological Centre of Children's Regional Hospital of Rostov-on-Don, Russia. Children were aged between 6 and 12 years with a diagnosis of acute lymphoblastic leukaemia. The control group consisted of 26 volunteer mother-child pairs recruited from educational institutions from the Rostov-on-Don and Rostov region. Control group children had no prior cancer diagnosis and were aged matched to the children with cancer.

\subsection{Procedure}

Ethics approval was obtained by the Southern Federal University research committee. Participants were briefed about the study, at which point consent was obtained for both mother and child. Mothers completed a demographic questionnaire before completing the "Cooperation Test" (CT) with their child. The CT was video recorded with participant consent. Mothers then completed the "Family Relationship Analysis" (FRA) ${ }^{[14]}$ and "Distress Thermometer Questionnaire" (DTQ). ${ }^{[26]}$ All children completed a projective drawing titled "My Social Circle", ${ }^{[27]}$ which was recorded. Children were later asked to discuss the content of their drawing.

\section{Measures}

\subsection{Demographics}

Participant place of residence, age of mother, age of child, and parental marital status was recorded. 


\subsection{Mother-Child interaction}

$\mathrm{CT}^{[28]}$ is an activity designed to assess the parent-child interaction. This measure combines several interaction tests based on an instruction and observation method. The type of activity is tailored to the developmental age, intellect and health needs of the child. The video recording of the session was observed and analyzed by researchers. The CT has been used frequently in Russian literature to assess the interaction between mother and child. ${ }^{[29-31]}$ The measure has shown both construct validity and reliability. ${ }^{[32]}$

\subsection{Family relationships}

The FRA ${ }^{[14]}$ is a 130 item scale consisting of 20 subscales reflecting several aspects of the family environment. It covers areas such as the familial traits, family structure and parenting styles. Parenting style is measured on several subscales including hyper-protection, ignoring the child's needs, excessiveness of demands and duties, preference of child qualities and bringing inter-spouse conflicts into the upbringing sphere. The FRA has previously been used within Russian literature and is a valid measure of family dynamics. ${ }^{[33]}$

\subsection{Distress}

The $\mathrm{DTQ}^{[26]}$ is a multifactorial measure designed to assess psychological, social, and/or spiritual experience that may interfere with one's ability to cope effectively. Responses are measured using a 10 point Likert scale. Additional questions within the scale identify unique coping strategies used. The DTQ has been shown to be a valid and reliable measure of psychological morbidity. ${ }^{[34]}$

\subsection{Child attitude}

"Social Circle"[27] is a diagnostic conversation activity designed to define the child's social circle and the types of relationships between them and the people around him/her with the assistance of graphic means (e.g., colour, intensity of connector lines). The place of the mother in the child's social circle, the modality of the child's attitude towards his/her mother (positive or negative), and the modality of the mother's attitude towards the child (according to the child's assessment) were taken into consideration. The drawing process is video recorded. Discussion of graphical means of self-expression reveals potentially unconscious experiences, conflict situations and ways of thinking. ${ }^{[25]}$ This measure is used frequently in Russian practice and scientific research. ${ }^{[35,36]}$ This measure has been proven to have construct validity. ${ }^{[32]}$

\section{Analyses}

Differences between groups were assessed using MannWhitney U test. Correlation analyses were conducted using Pearson's r. Data was analyzed using IBM SPSS Statistics 21.

\section{RESULTS}

Of the 26 children with cancer, $38 \%(n=10)$ lived in two parent families, while $88 \%(n=23)$ of the children in the control group lived in two-parent families $\left(\chi^{2}(1,26)=11.143\right.$, $p<.001)$. Ages of mothers in the oncology group ranged from 29 to 46 years old $(X=36.96, S D=5.54)$ and the age of mothers in the control group ranged from 30 to 53 years old $(X=39.92, S D=6.6)$. In terms of geographic location, $46 \%$ of mothers in the oncology group and 53\% of mothers in the control group lived in the city.

\subsection{Mothers' distress levels and coping strategies}

The mean score on the distress scale was significantly higher among mothers of children with cancer $(X=6.92, S D=1.97)$ than those from the control $(X=2.8, S D=2.34, p<.05)$. For mothers of children with cancer, average distress level was also higher for 2-parent homes $(X=6.38, S D=2.43)$ than single-parent homes $(X=3.62, S D=2.03, p<.05)$. Mothers' reported difficulties related to their distress in both groups are presented in Table 1. The methods that mothers adopted to cope with stress also differed between groups (see Table 2).

Table 1. Comparison of common distress-related experiences reported by mothers

\begin{tabular}{lll}
\hline $\begin{array}{l}\text { Distress-related } \\
\text { experiences }\end{array}$ & $\begin{array}{l}\text { Mothers of } \\
\text { children with } \\
\text { cancer }\end{array}$ & $\begin{array}{l}\text { Mothers of } \\
\text { children without } \\
\text { cancer }\end{array}$ \\
\hline $\begin{array}{l}\text { Common } \\
\text { Taking care of children } \\
\text { Household, financial and }\end{array}$ & $15(57.6)$ & $7(26.9)$ \\
transport problems & $9(34.6)$ & $6(23.1)$ \\
$\begin{array}{l}\text { Intimacy } \\
\text { Relationships with children }\end{array}$ & $7(26.9)$ & $2(7.7)$ \\
$\begin{array}{l}\text { Relationships with relatives } \\
\text { Emotional problems }\end{array}$ & $0(0)$ & $4(15.3)$ \\
$\begin{array}{l}\text { Depression } \\
\text { Fears }\end{array}$ & $13(50)$ & $4(15.3)$ \\
Nervousness & $16(61.5)$ & $1(3.8)$ \\
Grief & $20(76.9)$ & $4(15.3)$ \\
Anxiety & $18(69.2)$ & $0(0)$ \\
Loss of interest in usual & $24(92.3)$ & $7(26.9)$ \\
activities & $18(69.2)$ & $0(0)$ \\
\hline
\end{tabular}

Note. All variables have significant differences at $p<.05$. Results shown represent the number of responses of each distress-related experience, and the percentage of such response within each group. 
Table 2. Comparison of coping methods used by mothers of children with, and without cancer

\begin{tabular}{lllll}
\hline & Mother with ill-child & $\begin{array}{l}\text { 2-parent home - mother } \\
\text { with ill-child }\end{array}$ & $\begin{array}{l}\text { Single parent home - } \\
\text { mother with ill-child }\end{array}$ & $\begin{array}{l}\text { Mother with } \\
\text { health child }\end{array}$ \\
\hline Interaction with family and friends & $23(88.5)$ & $8(100)$ & $13(72.2)$ & $18(69.2)$ \\
Special literature reading & $16(61.5)$ & $6(75)$ & $9(50)$ & $0(0)$ \\
Belief in God, miracle & $11(42.3)$ & $3(37.5)$ & $8(44.4)$ & $0(0)$ \\
Husband support & $7(26.9)$ & $7(87.5)$ & $0(0)$ & $19(73.1)$ \\
Solitude & $3(11.5)$ & $0(0)$ & $3(16.7)$ & $1(3.8)$ \\
No coping method & $4(15.4)$ & $1(12.5)$ & $3(16.7)$ & $1(3.8)$ \\
Hobbies or relaxation & $0(0)$ & $0(0)$ & $0(0)$ & $18(69.2)$ \\
Work & $0(0)$ & $0(0)$ & $0(0)$ & $16(61.5)$ \\
\hline Note. Results shown represent the number of responses of each distress-related experience, and the percentage of such response within each group.
\end{tabular}

\subsection{Parenting style}

The mothers of children with cancer scored significantly higher $(p<.05)$ than mothers of children without cancer on the FRA scales of "Hyper-protection", "Indulgence", "Minimum sanctions", "Instability of upbringing style", "Expansion of parental feelings", "Upbringing insecurity", and "Loss phobia" (see Figure 1 for a comparison of parenting styles between the two groups of mothers).

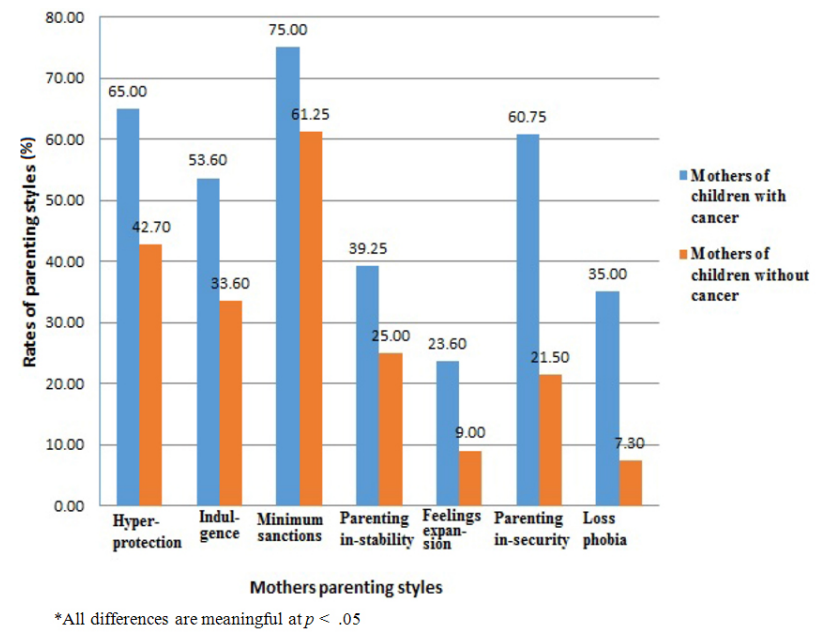

Figure 1. Mothers' parenting styles for children with, and without, cancer

\subsection{Child attitudes toward their mothers}

Children with cancer assigned their mothers more distant positions in the Social Circle Activity, with the majority placing their mothers in third place, while healthy children assigned their mothers first place in $70 \%$ of cases (see Table 3 ).

Only $3 \%$ of children with cancer described a negative attitude toward their mothers and none of the children with cancer reported a negative attitude of their mothers towards them. By contrast, $23 \%$ of the children without cancer described a negative attitude toward their mothers, while $15 \%$ described a negative attitude of their mothers towards them.
Table 3. Position of mothers in children's social circles

\begin{tabular}{lll}
\hline & $\begin{array}{l}\text { Children with } \\
\text { cancer }\end{array}$ & $\begin{array}{l}\text { Children } \\
\text { without cancer }\end{array}$ \\
\hline $1^{\text {st }}$ place $^{*}$ & $15 \%$ & $70 \%$ \\
$2^{\text {nd }}$ place $^{\text {rd }}$ place $^{*}$ & $11 \%$ & $15 \%$ \\
Did not mention mothers $^{*}$ & $52 \%$ & $12 \%$ \\
\hline
\end{tabular}

Note. ${ }^{*} p<.05$

\subsection{Mother-child interactions}

The CT produced data on 31 variables, with five of these variables showing significant differences between groups $(p<.05)$ : "Mutual support of initiative taking", "Discussion and comments on the process of mutual activity", "Addresses of the child with the mother's response", "Critical remarks of the mother towards the child", and "The larger part of interaction space occupied by the mother" (see Figure 2).

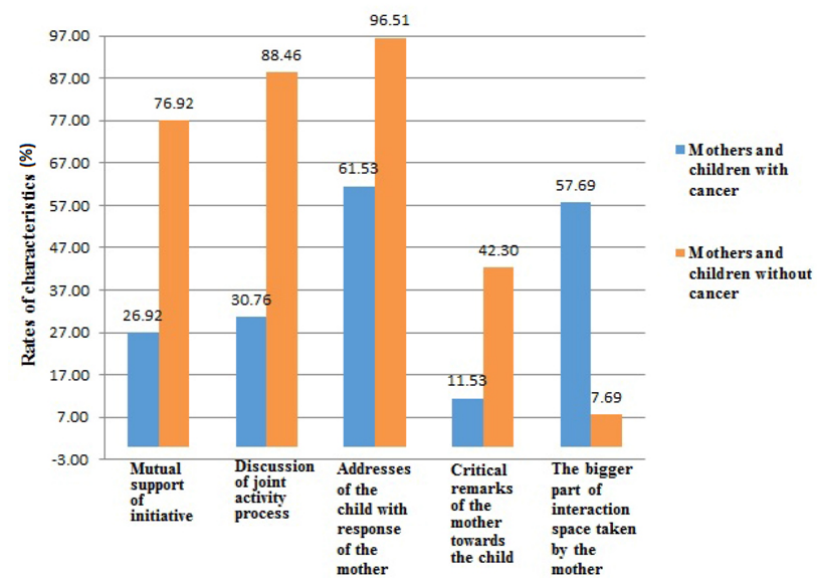

Figure 2. Characteristics of interactions between mothers and children with, and without, cancer

\subsection{Relationship between child attitude and parenting style}

The place occupied by mothers of children with cancer in the children's social circle and the scales of "Hyper-protection" 
$(r=.476, p<.01)$, "Ignoring the child's needs" $(r=.539, \quad(r=-.417, p<.05)$ and "Loss phobia" $(r=-.391 ; p<.05)$ $p<.01$ ), "Preference of child-like qualities" (i.e. infantalization) $(r=.469, p<.01)$, and "Bringing the inter-spouse conflict into the upbringing sphere" $(r=.478, p<.01)$ were positively correlated (see Table 4 ). The place occupied by mothers of children without cancer in the children's social circle and the scales of "Excessiveness of prohibitions"

were negatively correlated.

There was also a significant positive correlation between distress and the scales of "Ignoring the child's needs" $(r=.483$, $p<.01)$ and "Excessiveness of demands/duties" ( $r=.537$, $p<.01)$ among the mothers of children with cancer.

Table 4. Correlations between characteristics parenting styles, distress level, and the mother's place in the social circle of children with cancer

\begin{tabular}{|c|c|c|c|c|}
\hline & \multicolumn{2}{|c|}{ Distress thermometer } & \multicolumn{2}{|c|}{ Social circle } \\
\hline & $r$ & $\begin{array}{c}p \text { values } \\
\text { (two-sided) }\end{array}$ & $\boldsymbol{r}$ & $\begin{array}{c}p \text { values } \\
\text { (two-sided) }\end{array}$ \\
\hline Hyper-protection & -.018 & $.924^{*}$ & .476 & $.008^{* *}$ \\
\hline Ignoring the child's needs & .483 & $.007^{* *}$ & .539 & $.002^{* *}$ \\
\hline Excessiveness of demands and duties & .537 & $.002^{* *}$ & .352 & $.056^{*}$ \\
\hline Preference of child-like qualities (i.e. infantalization) & .097 & $.609^{*}$ & .469 & $.009^{* *}$ \\
\hline Bringing the inter-spouse conflict into the upbringing sphere & -.003 & $.988^{*}$ & .478 & $.008^{* *}$ \\
\hline
\end{tabular}

Note. ${ }^{*} p<.05 ; * * p .01$

\section{Discussion}

This study conducted an analysis of the relationships between Russian mothers and their children with, and without, cancer. The study addressed three aspects of mother-child relationships: distress level of mothers and the effect of distress on the mothers' parenting style; the children's assessment of their relationship with their mothers; and the unique characteristics of mother-child interactions.

As predicted, mothers of children with cancer showed higher distress levels than the mothers of healthy children, as found in past literature. ${ }^{[2,37,38]}$ Whilst mothers of children with cancer had higher distress related to taking care of children; household, financial and transport problems; and intimacy, mothers of children without cancer reported higher distress related to their relationships with their children and relatives. This may be due to the cancer experience resulting in greater support, or perceived support from relative, or potentially families dealing with cancer reluctant to report, or have difficulty acknowledging any strain in parent-child relationships. Children with cancer may also be less likely to report negative feelings towards their mothers. Two-parent homes of children with cancer also showed higher levels of distress than single-parent homes, which differs from past research. ${ }^{[39,40]}$ Given that common distress-related experiences include taking care of children and household chores, and that mothers in a relationship use partner-support as a common coping mechanism, higher distress may be due to a lack of quality support from their partner. Future work should consider further developing interventions to support parents, and marital dynamics through their child's cancer

Published by Sciedu Press experience. $^{[15,38,41]}$

Groups of mothers also varied in their methods for decreasing distress levels. The most common methods to reduce distress used by mothers of children with cancer were communication with close friends and family and reading literature related to the illness, compared with parents of healthy children who were more likely to use communication with one's spouse and relaxation. The study also showed that increased maternal distress was positively correlated with ignoring the child's needs for emotional contact and communication. Mothers' distress was also directly related to the increasing number of responsibilities of children in the family. Kazak and colleagues ${ }^{[2]}$ found similar outcomes, with parent distress correlating with less family communication. ${ }^{[22]}$

The process of raising children with cancer may differ substantially from that of raising healthy children. In the current study, mothers of children with cancer appeared to experience greater parenting insecurities compared with mothers of children without cancer. The parenting style of mothers of children with cancer appeared to be characterized by significantly more instability, extended parental feelings, and the tendency of mothers to satisfy their own need for intimacy at the expense of their children. The mothers of children with cancer also appeared more inclined to be overprotective toward their children, to indulge their child's demands, and to attempt to satisfy all of their needs, reflecting international literature ${ }^{[18,20,43]}$ Results are consistent with past studies about mothers' relationships with children who have no serious illnesses, but have regular acute respiratory viral 
infections. ${ }^{[20]}$ Our research also suggests, Russian children with cancer appear to have fewer duties within families, and mothers may be likely to punish them less often than mothers of children without cancer, which is echoed in other studies. $^{[23,44,45]}$

Results also showed that children without cancer were more likely to give their mothers a higher place within their social circle, in comparison to children with cancer, who tended to place their mothers in a more distant position. During joint tasks, analysis showed that these mothers-child dyads were less mutually supportive of one another, and communicated less frequently regarding the process of the activity. This may potentially be a coping strategy for children who may feel the need to emotionally separate from their family. It is possible that children with cancer may also place their mothers further away in their social circle because of the degree of their mother's over protectiveness. Future research should examine the child's reasoning for the placements, and how family dynamics influence the child's placement of their mother in their social circle.

The results of this study provide the first Russian research detailing the dynamic and multifaceted nature of the motherchild relationship when a child has cancer. In an attempt to identify the unique characteristics within maternal parenting styles and their role within mother-child interactions, this study aimed to extend upon previous Western literature using a Russian framework. The strengths of this research include the homogeneity of the sample in terms of age and in the children's illness. The study was further strengthened by the collection of observational and self-report data. This study however must be interpreted with several limitations. Firstly, the small sample size limits the ability to generalize the findings. A larger sample size would have been able to shed more light on the differences within groups of families of a child with an illness. Due to an administrative error, it is not possible to further determine any differences and control for single vs. two-parent homes in analyses. Future research should consider looking at within group differences of the interactions between mothers and ill-child. Although an advantage of this paper is that it reports on a Russian sample, a limitation exists due to the use of Russian measures that have not been previously used in Western literature. This leads in difficulties in comparing this research outside of Russian literature. Finally, the focus of this study was limited to the "mother-child" relationship. Future research should consider examining the relationships with the child throughout the family system.

Regardless of the study's limitations, this research adds a unique contribution to the research literature. This study identified a link between distress and the mother-child relationship, highlighting the possibility of defining the characteristic features of parenting style among mothers of children with cancer. Determining the differences in parenting and coping strategies of parents with their child with and without an illness will provide insight in to the factors and barriers for effective parenting. The findings will further contribute towards focused psychotherapeutic interventions aimed at decreasing distress among mothers and improving mothers' relationship with their children. ${ }^{[16]}$

\section{ACKNOWLEDGEMENTS}

The authors are grateful to Illia Mstibovskyi, Olga Patrakeyeva, and Kate Marshall for their assistance in this research. Claire Wakefield is supported by a Career Development Fellowship from the National Health and Medical Research Council of Australia (APP1067501) and an Early Career Development fellowship from the Cancer Institute of NSW (ID: 11/ECF/3-43).

\section{CONFLICTS OF INTEREST Disclosure}

The authors declare no conflicts of interest.

\section{REFERENCES}

[1] Orbuch TL, Parry C, Chesler M, et al. Parent-child relationships and quality of life: Resilience among childhood cancer survivors. Family Relations. 2005; 54(2): 171-83. http://dx.doi.org/10.1111/j $.0197-6664.2005 .00014 . \mathrm{x}$

[2] Kazak AE, Barakat LP, Alderfer M, et al. Posttraumatic stress in survivors of childhood cancer and mothers: Development and validation of the Impact of Traumatic Stressors Interview Schedule (ITSIS). Journal of Clinical Psychology in Medical Settings. 2001; 8(4): 30723. http://dx.doi.org/10.1023/A:1011977031826

[3] Kupst MJ. Long-term family coping with acute lymphoblastic leukemia in childhood. Stress and Coping in Child Health. 1992; 242-61.
[4] Wallander JL, Varni J. Effects of pediatric chronic physical disorders on child and family adjustment. Journal of Child Psychology and Psychiatry. 1998; 39(1): 29-46. PMid: 9534085. http: //dx.doi.org/10.1017/S0021963097001741

[5] Filippova GG. Psychology of motherhood: Teacher guide. Moscow: Institute of Psychotherapy; 2002.

[6] Eidemiller EG, Justitsky VV. Family psychology and psychotherapy (monograph). SPb. 2007.

[7] Varga AJ. Types of parental attitudes. Samara. 1997.

[8] Grusec JE. Parents' attitudes and beliefs: Their impact on children's development, 2nd ed. In: Tremblay RE, Boivin M, Peters RD, editor. Montreal, Quebec: Centre of Excellence for Early Childhood 
Development and Strategic Knowledge Cluster on Early Child Development; 2008.

[9] Vylegzhanina GG. The role of motivation in the personality development of ill child in the conditions of particular social development situation. 120th Anniversary of The Opening of The First Psychological Laboratory: Materials of The Russian Scientific-Practical Conference. 2005. 71-8p.

[10] Smirnova YO, Bykova MV. Experience of constructing a diagnostic technique of parental attitude towards a child. Family psychotherapists and family psychologists: Who are we? Sankt Petersburg. 2001.

[11] Baumrind D. Child care practices anteceding three patterns of preschool behavior. Genetic psychology monographs. 1967; 75(1): 43-88.

[12] Maccoby EE, Martin JA. Socialization in the context of the family: Parent-child interaction. Handbook of child psychology: formerly Carmichael's Manual of child psychology/Paul H Mussen, editor. 1983.

[13] Hawes DJ, Dadds M. Assessing parenting practices through parentreport and direct observation during parent-training. Journal of Child and Family Studies. 2006; 15(5): 554-67. http://dx.doi.org/1 $0.1007 / \mathrm{s} 10826-006-9029-\mathrm{x}$

[14] Eydemiller EG. Techniques of family diagnostics and psychotherapy. Teacher guide Psychodiagnostics: to a teacher, doctor, psychologist. 1996(1).

[15] Pinquart M. Do the parent-child relationship and parenting behaviors differ between families with a child with and without chronic illness? A meta-analysis. Journal of pediatric psychology. 2013; 38(7): 708-21. PMid: 23660152. http://dx.doi.org/10.1093/jpeps y/jst020

[16] Morawska A, Calam R, Fraser J. Parenting interventions for childhood chronic illness A review and recommendations for intervention design and delivery. Journal of Child Health Care. 2015; 19(1): 5-17. PMid: 24486817. http://dx.doi.org/10.1177/13674935134 96664

[17] Twigg J, Atkin K. Carers perceived: policy and practice in informal care. Michigan, USA: Open University Press; 1994.

[18] Young B, Dixon-Woods M, Findlay M, et al. Parenting in a crisis: conceptualising mothers of children with cancer. Social Science \& Medicine. 2002; 55(10): 1835-47. http://dx.doi.org/10.1016 /S0277-9536(01) 00318-5

[19] Nikolayeva VV, Arina GA. A seriously ill child, traits to the portrait. School of Health. 1994; 2(2): 86-95.

[20] Arina GA, Kovalenko NA. Frequently ill children. What are they like? School of Health. 1995; 2(3): 116-25.

[21] Sokolova ET, Nikalaeva VV. Particularities of personality in cases of borderline disorders and somatic diseases. Moscow, SvR-Argus. 1995.

[22] Aralova MP, Aslanyan KS, Polevichenko YV, et al. Psychological research of parental attitude towards preschoolers at the stage of remission in case of acute lymphoblastic leukemia. Social and psychological problems in pediatric oncology: Materials of the first all-Russian conference with International participation; Moscow. 1997.

[23] Kireyeva IP. Psychosocial aspects of pediatric oncology. Social and psychological problems in pediatric oncology: Materials of the first all-Russian conference with International participation; Moscow. 1997. 95-7p.

[24] Walker LS, Garber J, van Slyke DA. Do parents excuse the misbehavior of children with physical or emotional symptoms? An investigation of the pediatric sick role. Journal of Pediatric Psychol- ogy. 1995; 20(3): 329-45. PMid: 7595820. http://dx.doi.org/1 $0.1093 /$ jpepsy/20.3.329

[25] Uruntaeva GA, Afonkina UA. Case-study of child psychology. Vlados, Moscow. 1995.

[26] Grassi L, Holland JC, Johansen C, et al. Psychiatric concomitants of cancer, screening procedures, and training of health care professionals in oncology: the paradigms of psycho-oncology in the psychiatry field. Advances in Psychiatry. 2005; 2: 59-66.

[27] Andruschenko TY. Conversation "Social Circle" in the diagnosis of the social situation of the child. Journal of Practical Psychology. 1998; 4: 86-91

[28] Burmenskaya GV, Zakharova EI, Karabanova OA. Developmental approach in counseling children and adolescents. 2007; 287-304.

[29] Dueva AA. Interaction with the mother in children born as a result of in vitro fertilization (IVF): Attachment and parenting style features. Psychological Science and Education. 2014; 6(2): 293-305. http://dx.doi.org/10.17759/psyedu. 2014060225

[30] Pupyreva EV. Emotional attachment to mother as the factor of formation of autonomy in middle childhood: Abstract of PhD thesis. Moscow Moscow University. 2007.

[31] Shvedovskaya AA. Specific of Emotional Experience of Child-Parent Relations and Child-Parents Interactions in Older Preschoolers: Abstract of PhD thesis. Moscow Moscow University. 2006.

[32] Ahundzhanova C. Development of preschool speech in productive activities. Preschool education. 1983; 6: 34-6.

[33] Vladimirovna LM, Ilona D. The dependance of the level of perfectionism and typology of teenagers on the type of education in the family inharmonious perfectionism and parenting type. Innovations in Science. 2015; 5(42).

[34] Gil F, Grassi L, Travado L, et al. Use of distress and depression thermometers to measure psychosocial morbidity among southern European cancer patients. Supportive Care in Cancer. 2005; 13(8): 600-6. http://dx.doi.org/10.1007/s00520-005-0780-0

[35] Koneva EV. Determinants and Criteria of Social Adaptation of Schoolchildren with Special Educational Needs. Psychology. 2007; 4: 132-9.

[36] Sergeenko EN, Kuzmina NN. Features of communicative competence of young school children with different type of temperament. Psychology and Pedagogy: methodology and problems of practical application. 2012; 28.

[37] Pai ALH, Greenley RN, Lewandowski A, et al. A meta-analytic review of the influence of pediatric cancer on parent and family functioning. Journal of Family Psychology. 2007; 21(3): 407. PMid: 17874926. http://dx.doi.org/10.1037/0893-3200.21.3.4 07

[38] Cousino MK, Hazen RA. Parenting stress among caregivers of children with chronic illness: a systematic review. Journal of pediatric psychology. 2013; 38(8): 809-28. PMid: 23843630. http: //dx.doi.org/10.1093/jpepsy/jst049

[39] Iobst EA, Alderfer MA, Sahler OJZ, et al. Brief report: Problem solving and maternal distress at the time of a child's diagnosis of cancer in two-parent versus lone-parent households. Journal of Pediatric Psychology. 2009; 34(8): 817-21. PMid: 19129268.

[40] Compas BE, Williams RA. Stress, coping, and adjustment in mothers and young adolescents in single-and two-parent families. American Journal of Community Psychology. 1990; 18(4): 525-45. PMid: 2075890. http://dx.doi.org/10.1007/BF00938058

[41] Silva-Rodrigues FM, Pan R, Sposito AMP, et al. Childhood cancer: Impact on parents' marital dynamics. European Journal of Oncology Nursing. 2016; 23: 34-42. http://dx.doi.org/10.1016/j .ejo n.2016.03.002 
[42] Mikheev AA, Manelis NG. Features of family relationship between parents and children with asthma. School of Health. 1996; 4: 116-7.

[43] Drotar D. Psychological perspectives in chronic childhood illness. Journal of Pediatric Psychology. 1981; 6(3): 211-28. PMid: 7288529 http://dx.doi.org/10.1093/jpepsy/6.3.211

[44] Chao C, Chen S, Wang C, et al. Psychosocial adjustment among pediatric cancer patients and their parents. Psychiatry and Clinical Neurosciences. 2003; 57(1): 75-81. PMid: 12519458. http: //dx.doi.org/10.1046/j.1440-1819.2003.01082.x

[45] Hillman KA. Comparing child-rearing practices in parents of children with cancer and parents of healthy children. Journal of Pediatric Oncology Nursing. 1997; 14(2): 53-67. PMid: 9144975. http://dx.doi.org/10.1177/104345429701400203 